\title{
The Application of Parallel Corpora in Translation Teaching
}

\author{
Jingang Bai \\ School of Foreign Languages, Chifeng University, Chifeng, China \\ 1461942076@qq.com
}

Keywords: Translation teaching; Parallel corpora; Word stuffing; Translation learning

\begin{abstract}
In recent years, the development of corpora-based study provides language learners and teachers with great opportunities to have access to parallel corpora in their translation teaching and learning. In this paper, the author conducts an experiment to testify if the parallel corpora can help students to solve the problem of word stuffing in the process of translation teaching.
\end{abstract}

\section{Introduction}

'Corpora' is a Latin word, which means 'body', and simply refers to any collection of more than one text. However, this term has a more specific definition within the borders of linguistics and corpus linguistics. According to Sinclair (1994) corpus is a "collection of pieces of language that are selected and ordered according to the explicit linguistic criteria in order to be used as the sample of the language" (cited in PEARSON 1998:42). McEnery and Wilson (2001:32) defines corpus as: "a finite-sized body of a machine readable text, sampled to be maximally representative of the language variety under consideration." Many scholars put forward definition of corpus in various perspectives. Overall, we can generate some points from the definitions. First, corpora are collections of authentic texts. Second, the texts in corpora are sampled to reveal many aspects of language use under study. Third, corpora work as a form of various computer programs. So, undoubtedly, working with corpus can revolutionize the way of learning and teaching. In recent years, parallel corpora seldom have been applied in translation learning and teaching since many scholars have been more focused on the application of parallel corpora in language learning and teaching, especially, in writing and speaking. Therefore the author conducted an experiment to investigate the positive effect of parallel corpora in in the process of translation to help subjects to solve the problem of word stuffing.

\section{Objectives and Subjects}

In translation practice, word stuffing is one of the difficult problems for students in the process of translation. In the experiment, the author mainly focuses on the translation of typical expressions that the students translate with difficulty since parallel corpora can provide real-context information for students to deal with the problem.

The general objective of the paper is to testify if subjects who translate with the help of parallel corpora can perform better than the other group of subjects who translate with conventional dictionaries when two groups of subjects working with the same translation material. Specifically, the research is to testify if parallel corpora can help subjects solve the problem of word stuffing so that subjects can get more native translation versions. Subjects are 80 sophomores from the computer department of Chifeng University, who are divided into two groups in the experiment. One group of subjects translate with parallel corpora, the other group of subjects translate with conventional dictionaries. There are several reasons for choosing the subjects: the subjects are from computer department, so they have the basic computer skills which are necessary to operate parallel corpora; they are going to attend the examination of CET4. C-E translation is one part of it; as sophomore, they have got the basic translation skills to work with identical translation materials with the help of translation tools. 


\section{Test Material and Tools}

Test materials are sentences translations and paragraphs translations selected from CET 4 Model test. PACCEL (Parallel Corpus of Chinese EFL learners) and several online parallel corpora will be used in the experiment. PACCEL is the first large scale Chinese-English parallel corpora of Chinese English foreign language learners in China, and the other two online parallel corpora are The Babel English-Chinese Parallel Corpus in CQPweb available at http://124.193.83.252/cqp/ and an English-Chinese online parallel corpus is available at http://www.luweixmu.com/ powered by professor Lu Wei from Overseas Education College of Xiamen University.

In the experiment, concordance Paraconc works as the corpus analyzing tool. It is a bilingual or multilingual concordance designed and produced by Professor Michael Barlow in University of Auckland, which can be used in contrastive analyses, language learning and teaching, translation studies and training and so on.

\section{Procedure of Experiment}

The experiment lasts about 8 weeks from April 2015 to June 2015, which mainly included two phases: preparation and implementation phase.

\section{Preparation}

Since the experiment is conducted to compare and contrast two groups of subjects' performance with different translation tools to translate the same material, the author prepare two groups of subjects, conventional C-E dictionaries and several parallel corpora as well as translation materials.

Subjects in the control group with conventional dictionaries will work in a traditional way that after subjects finish the translation tasks in class or after class, they are required to bring them back to discuss in class. Finally, the author presents the best translation to the class.

Parallel corpus is a kind of computer software, firstly, the author would teach subjects to operate corpora and learn about the corpora analysis tools and how to extract transnationally-relevant information from corpora. On this basis, subjects in experimental group are required to translate the same materials with parallel corpora.

\section{Implementation}

Both subjects using conventional dictionaries and parallel corpora are required to translate eight pieces of C-E translation materials, once a week as assignment. Then the author compares the translation versions from two groups and make conclusion. In the experiment, the author mainly compares the translation of typical expressions, which students usually make mistake in the process of translation, to testify the positive effect of parallel corpora in translation practice, which can help students avoid making typical mistakes and get more native translation versions with higherquality.

\section{Results and Analysis}

In translation, because of lacking the thorough understanding of the meaning of English words, students usually pile up all equivalents to make expressions in their translation regardless of the actual meaning each individual item conveys, which always leads to word stuffing and so-called Chinglish in their translation products. The parallel samples in parallel corpora can help students to solve the problem. Students can get insight the massage the equivalent transfer through comparing and analyzing the parallel samples. The author chooses the following three easy-to-hard examples to prove the point.

Example 1 changge he tizuqiu shi ta zui xihuan de shiqing.

Translation A: Singing songs (unacceptable expression) and playing basketball with others are of his favorite things. 
Translation B: Singing and playing basketball with others are of his favorite things.

Example 2 suizhe jinkou xianjin de chanpin he fuwu, fazhan zhong guojia tongshi ye cong jingji fada guojia huoqu le yixie jishu.

Translation A: Along with the more sophisticated goods and services imported, developing countries also acquire some of the technologies from developed countries.

Translation B: Along with the more sophisticated goods and services imported, developing countries also acquire some of the technologies from economically developed countries (unacceptable expression).

Example 3 wo men yao guangfan puji kexue wenhua zhishi.

Translation A: We need to extensively popularize (unacceptable expression) science and culture.

Translation B: We need to popularize science and culture.

In this aspect, parallel corpora turn out to be useful resources, which can offer such information from parallel samples that in the first sentence, "singing" has the meaning of "change". So it is unnecessary to translate it as "singing songs". It is the same with the next two sentences, "developed" in "developed countries" means "jingji fada de", so "economically" would lead to word stuffing in translation. In the third example, the word "popularize" also contains the degree of "extensively", so "extensively" should be omitted. All the information on the accurate meaning of each individual item can be obtained from parallel corpora, so the students who translate with parallel corpora do much better job than the students without the help of parallel corpora. At the same time through consulting the way source text massages have been transferred into the target language massages in corpora, students can get insight into the difference between the source language and the target language, and gain the contrastive knowledge about the two languages involved. Parallel corpora can provide students with the information on how similar meanings are expressed in text having similar functions in two languages and students know clearly that some words can't be directly translated into the target language, which may cause misunderstanding. For example, the Chinese phrase "kua shiji qingnian yidai", most students understand it as "kua shiji qingnian yidai", so they are likely to translate it as "the young people of a generation who cross century", which is the typical mistake with the problem of word stuffing that students usually make. If students query the parallel corpora, they will see the native translation is "the Young generation of the new century" or "the young generation of the turn of century". Moreover, through observing the parallel samples from parallel corpora, students will see sometimes "the young people" or "the young generation" can be equivalent to "kua shiji qingnian yidai". There is no doubt that parallel corpora provide an easy access for students to avoiding word stuffing not only in translation of words and phrases even in the translation of whole sentences. The author chooses next three examples to prove the point.

Example 4 zhongguo zui zhongyao de jieri shi chunjie, zui renao de jieri ye shi chunjie.

Translation A: In China, the most important festival is Spring Festival; the most exciting festival is also Spring Festival. (With the problem of word stuffing)

Translation B: In China, the most important festival is Spring Festival, which is also the most exciting.

Example 5 meihua xiangzheng jianqiang, meigui xiangzheng aiqing, hehua xiangzheng qingbai, lanhua xiangzheng guiyin.

Translation A: Plum represents determination, rose represents love, lotus represents purity, and orchid represents seclusion. (With the problem of word stuffing)

Translation B: Plum represents determination, rose love, lotus purity, and orchid seclusion.

Example 6 tamen shefa xiang jiejue gongdian he gongshui de lianjie wenti.

Translation A: They grappled with the problem of connecting the electricity and water supplies. But it seems that the electricity proved simple compared with the water supplies. (With the problem of word stuffing)

Translation B: They grappled with the problem of connecting the electricity and water supplies. But it seems that the former proved simple compared with the latter. 
Those three examples prove that there are many differences between China and English in syntactic level that sometimes it is unnecessary to translate each word. In the process of translation, some can be omitted; some can be substituted, which usually need some translation strategies that can't be obtained from the traditional dictionaries. Students can get insight into those translation strategies that professional translators use in the parallel samples to deal with the same problem so that they can get more native translation products. In the first example, using an attributive clause instead of a short sentence to translate "zui renao de jieri ye shi chunjie" is more native. The same to the second translation, it can be simplified by omitting the translation of next three "represents", which is due to avoiding repetition. In English, pronouns can be used to substitute some words mentioned before, so in translation, they can also be used to produce native translation. Example three is a typical translation of using the expression "the former" to substitute the mentioned information in the sentence "the electricity".

For some students, translation means translating each word into target language regardless of the difference in expression between the two languages, which may lead to unacceptable translation with the problem of word stuffing. Parallel corpora can be valuable resources for students to acquire useful information to solve the problem. Students can observe the parallel samples from corpora to see the difference in syntactic structures between the two languages and the strategies the professional translators use to deal with the same problems they encounter later. Next table is about the result of translation on "kua shiji qingnian yidai".

Table 1 "kua shiji qingnian yidai"

\begin{tabular}{|l|c|c|c|c|}
\hline \multicolumn{1}{|c|}{ kua shiji qingnian yidai } & \multicolumn{2}{c|}{$\begin{array}{c}\text { The experimental group } \\
\text { (with corpora) }\end{array}$} & \multicolumn{2}{c|}{$\begin{array}{c}\text { The control group } \\
\text { (without corpora) }\end{array}$} \\
\hline \multicolumn{1}{|c|}{ Acceptable expressions } & figure & percentage & figure & percentage \\
\hline $\begin{array}{l}\text { the young generation of the } \\
\text { new century }\end{array}$ & 7 & 17.5 & 0 & 0 \\
\hline the young people & 5 & 12.5 & 0 & 0 \\
\hline the young generation & 9 & 10 & 3 & 7.5 \\
\hline the new century youth & 6 & 2.5 & 1 & 2.5 \\
\hline \multicolumn{1}{|c|}{ Total } & 27 & 67.5 & 4 & 10 \\
\hline Unacceptable expressions & figure & percentage & figure & percentage \\
\hline $\begin{array}{l}\text { the young people of a } \\
\text { generation who cross the } \\
\text { century }\end{array}$ & 2 & 5 & 6 & 15 \\
\hline $\begin{array}{l}\text { Cross-century young } \\
\text { generation people }\end{array}$ & 1 & 2.5 & 4 & 10 \\
\hline the youth of crossing century & 1 & 2.5 & 3 & 7.5 \\
\hline $\begin{array}{l}\text { A generation of youth } \\
\text { extending into the century }\end{array}$ & 1 & 2.5 & 0 & 0 \\
\hline $\begin{array}{l}\text { Other unacceptable } \\
\text { expressions }\end{array}$ & 8 & 45 & 23 & 57.5 \\
\hline \multicolumn{1}{c}{ Total } & 13 & 32.5 & 36 & 90 \\
\hline
\end{tabular}

"kua shiji qingnian yidai" is a difficult expression for students to translate. Most students are confused at how to put the translation of "kua shiji", "qingnian"and "yidai" in correct order to produce the expression in English. Actually the problem doesn't exist in the word order, because the students can't produce the correct translation no matter in which order they put the translated words together. Without corpora, the students who produce the acceptable expressions only rely on their previous translation experience or just putting words together in random order. From the table, we can see in the control group, only $10 \%$ of students' translations are acceptable, however, in the experimental group, there are $67.5 \%$ of students finding the acceptable expressions with the help of 
parallel corpora. In the control group, $90 \%$ of students' translations are unacceptable with the problem of mainly stuffing words, while in the experimental group, there are only $32.5 \%$ students creating nonnative expressions. Parallel corpora help students to reduce the problem of word stuffing from $90 \%$ to $32.5 \%$ in translation practice. Moreover, parallel corpora are also of great help for students to produce native target sentences without the problem of word stuffing, which enables students to avoid creating Chinglish. Taking the translation of the sentence "zhongguo zui zhongyao de jieri shi chunjie, zui renao de jieri ye shi chunjie." as an example, In fact, it is much easier for students to do the translation, but it is worth mentioning that in the experimental group there are $65 \%$ students translating it into idiomatic English which is native and accepted by teachers and native speakers -- "In China, the most important festival is Spring Festival, which is also the most exciting", however, in the control group almost $70 \%$ of students are influenced by Chinese thinking mode translating the sentence into "In China, the most important festival is Spring Festival, the most exciting festival is also Spring Festival", which is a Chinglish sentence. In the experiment, the author also finds that parallel corpora turn out to be useful translation tools for students to avoid Chinglish. The following table is about the translation of the sentence "zhongguo zui zhongyao de jieri shi chunjie, zui renao de jieri ye shi chunjie."

Table 2 Translation of the Sentence

\begin{tabular}{|c|c|c|c|c|}
\hline Sentence (1) & \multicolumn{2}{|c|}{$\begin{array}{c}\text { Experimental group } \\
\text { (with corpora) }\end{array}$} & \multicolumn{2}{c|}{$\begin{array}{c}\text { Control group } \\
\text { (without corpora) }\end{array}$} \\
\hline Translations & figure & percentage & figure & percentage \\
\hline $\begin{array}{c}\text { Acceptable } \\
\text { translations }\end{array}$ & 26 & 65 & 12 & 30 \\
\hline $\begin{array}{c}\text { Unacceptable } \\
\text { translations }\end{array}$ & 14 & 35 & 28 & 70 \\
\hline
\end{tabular}

\section{Findings and Conclusion}

For some students, translation means translating each word in order to pile them together especially translating some complicated expressions, which always leads to word stuffing in the target language. Word stuffing has ever been a trouble for students and teachers. For some complicated phrases, they can't be translated by following the rules, so teachers are not able to teach students some relevant knowledge because there are no real communicative situations. From the translation of the complicated phrase "kua shiji qingnian yidai", the author finds that parallel corpora also can solve the problem and help students reduce the word stuffing. Students can find well-established translations from lots of parallel samples, and sometimes there are more simple translations, such as "the young people" and "the young generation". In the experiment, the author also finds that with the help of parallel corpora, students also make a great progress in translating the whole sentences without unnecessary translations, which reduces word stuffing in the sentences. So the translations of students in the experimental group are more acceptable in English. The effect of parallel corpora is proved by the translation of the sentence "zhongguo zui zhongyao de jieri shi chunjie, zui renao de jieri ye shi chunjie."

So it can be concluded that parallel corpora can help students solve the problem of word stuffing. In the experiment, parallel corpora show their great potential in helping students produce native and natural translations without word stuffing and Chinglish, which is shown by the results of comparing the translation of phrase "kua shiji qingnian yidai" between the experimental group and the control group.

\section{References}

[1] Kennedy, G. An Introduction to Corpus Linguistics [M]. Beijing: Tsinghua University Press, 1998: 11-13. 
[2] Pearson, Jennifer. Terms in Context [M]. Amsterdam/Philadephia: John Benjamin Publishing Company. 1998.

[3] McEnery, Tony / Wilson. Corpora Linguistics: An introduction [M]. Edingurburgh: Edingurburgh University Press. 2001.

[4] Baker, Mona. Corpus Linguistics and Translation Studies: Implication and Applications. In Baker, Mona / Francis, G ILL / Tognini-Bonelli. Elena (edc) Text and Technology: In honor of John Sinclair [C]. Amsterdam/Philadelphia: John Bemjamins, 1993: 233-250.

[5] Bernardini. S. A 'Trainee'Translator's Perspective on Corpora [M]. Paper Presented at Corpus Use and Learning to Translate. Held at Bertinoro. November. 1997.

[6] Bowker, Lynne / Pearson, Jennifer. Working with Specialized Language: A Parallel guide to using corpora [M]. London/New York: Routledge. 2002.

[7] Bowker, Lynne. Towards a methodology for exploiting specialized target language corpora as translation resources [J]. International Journal of Corpus Linguistics, 2000a: 17-52.

[8] Crystal, D. Stylistic linguistics: Studies in Honour Profiling [J]. in Aijmer \&Altenberg (eds.). English Corpus of Jan Svartvik [C]. 1991:75-78.

[9] Hansen, silvia / Teich, Elke 2002. The creation and exploitation of a translation reference corpus. In Yuster-Rodrigo, Elena (ed) Language References for Translation Work and Research: LREC 2002 Workshop Proceedings [C]. Las Palmas de Gran Canada, 2002: 1-5.

[10]Jiang, Xiaoping / Rij-Heyligers, Josta V. 2008. Parallel Corpus in Translation Studies: An International Approach. In Xiao, Richard / He Lianzhen / Yue, Ming (eds) Processings of the International Symposium on Using Corpora in Contrastive and Translation Studies (UCCTS 2008) [C]. Retrieved Feb 1, 2008, from: <http://www.Lancs.ac.uk/fass/projects/corpus/UCCTS2008Proceedings/>. 